\title{
Clinical Assessing and Risk Factor Analysis of Preoperative Anxiety and Depression in Patients with Thyroid Cancer
}

\author{
Qian Ye, Yuhua Ma*, Ming Xie \\ Department of Thyroid Gland Breast Surgery, The First Affiliated Hospital of Jinan University, Guangzhou, China \\ Email address: \\ 630761589@qq.com (Qian Ye), mayuhua2110@126.com (Yuhua Ma),595097630@qq.com (Ming Xie) \\ ${ }^{*}$ Corresponding author
}

To cite this article:

Qian Ye, Yuhua Ma, Ming Xie. Clinical Assessing and Risk Factor Analysis of Preoperative Anxiety and Depression in Patients with Thyroid Cancer. American Journal of Nursing Science. Vol. 9, No. 6, 2020, pp. 407-410. doi: 10.11648/j.ajns.20200906.13

Received: October 26, 2020; Accepted: November 5, 2020; Published: November 16, 2020

\begin{abstract}
Objective: According to evaluating the preoperative depression and anxiety of patients with thyroid cancer, relevant risk factors were analyzed and effective intervention measures were discussed. Methods: We collected 111 participants' information which the patients were diagnosed as thyroid cancer. They were diagnosed in the hospital and join our study from June 2018 to February 2020. In the study, we provide some questionnaires to participants, and collect the information of patient from hospital database. After that, our researchers get the result through analysis and statistics. We collect the related data, that contains anxiety assessment, depression assessment, gender, age, education, occupation, family per capita income, payment method, marital status, previous surgery history, familiarity with surgery, history of alcohol use, smoking history, sleep quality. Result: more participants in research have anxiety than the participants who have depression problems, the none level of two assessment are $41.44 \%$ vs $49.55 \%$. In similar, anxiety assessment group has higher score than that of depression assessment group in the result $(9.53 \pm 3.84 \mathrm{vs} 8.74 \pm 3.23)$. In different general data the incidence, the elements which are the average monthly income of the family, pay method and history of smoking, sleep condition are statistical significance. Conclusion: the important factors of anxiety and depression contain education level in high school or above, payment at their own expense and poor sleep quality in patients with thyroid cancer before surgery.
\end{abstract}

Keywords: Thyroid Cancer, Anxiety, Depression

\section{Introduction}

Thyroid cancer is a common malignant tumor of the endocrine system, which originates from parafollicular or follicular thyroid cells [1]. Base on the report, all cancer cases of all world had $3.4 \%$ is thyroid cancer [2]. Approximately 550,000 cases of thyroid cancer are diagnosed each year, that the researches show patients are 10.2 cases per 100,000 women and 3.1 cases per 100,000 men, so $75 \%$ of thyroid cancer patients are women worldwide [3-5]. Thus, Thyroid cancer is the 5th most common cancer in women, accounting for $5 \%$ of all new cancers diagnosed in 2012 [6]. In addition, some researchers think thyroid cancer is highly dependent on changes inhuman hormone levels so that Surgical treatment is the main treatment for thyroid cancer [7]. Due to the characteristics of thyroid disease and special anatomical location, anxiety and depression are common in patients before surgery, that patients often have mental health problems in hospital [8].

Most patients who are diagnosed as thyroid cancer will receipt the treatment of thyroidectomy, but less patients will be treated with radioactive iodine ablation therapy and thyroid hormone suppression $[9,10]$. Surgery of the thyroid gland is increasingly popular performed as ambulatory procedures in China [11]. These treatments lead to excellent long-term cancer outcomes for the vast majority of patients. As a result, the large pool of 800,000 thyroid cancer survivors continues to grow worldwide $[12,13]$. The aim of this paper was to assess and analyze the preoperative anxiety and depression in patients with thyroid carcinoma.

\section{Methods}

\subsection{Participants Enrollment and Survey Methods}

We collected 111 participants' information which the patients 
were diagnosed as thyroid cancer. They were diagnosed in the hospital and join our study from June 2018 to February 2020. In the study, we provide some questionnaires to participants, and collect the information of patient from hospital database. After that, our researchers get the result through analysis and statistics. The collected information includes anxiety assessment, depression assessment, gender, age, education, occupation, family per capita income, payment method, marital status, previous surgery history, familiarity with surgery, history of alcohol use, smoking history, sleep quality. The anxiety assessment and depression assessment were collected by Hospital Anxiety and Depression Scale (HADS) [14-16]. Another information was collected from homemade basic information questionnaire and hospital database.

\subsection{Statistical Analysis}

We used SPSS 23.0 software package for statistical processing. The quantitative data were expressed as mean \pm standard deviation $( \pm \mathrm{s})$, and two independent sample $\mathrm{T}$ tests were used for comparison between the two groups. The qualitative data were expressed as percentage and X2 test was used. The risk factors with significant differences were compared between the two groups for binary Logistic regression analysis. $\mathrm{P}<0.05$ was considered significant.

\section{Result}

Our researchers collect the information of anxiety assessment and depression assessment by HADS, the higher the score means more severe the symptoms of anxiety and depression in the study (Table 1). In detail, more participants in research have anxiety than the participants who have depression problems, the none level of two assessments are $41.44 \%$ vs $49.55 \%$. In similar, anxiety assessment group has higher score than that of depression assessment group in the result $(9.53 \pm 3.84$ vs $8.74 \pm 3.23)$. In addition, the research result shows more participants who have anxiety problem or depression problem provide moderate level assessment.

Table 1. Hospital Anxiety and Depression Scale Assessment Result, $n$ (\%).

\begin{tabular}{|c|c|c|c|c|c|}
\hline Projects & None level & Mild level & Moderate level & Severe level & Score \\
\hline Anxiety & $46(41.44)$ & $20(18.02)$ & $35(31.53)$ & $10(9.01)$ & $9.53 \pm 3.84$ \\
\hline Depression & $55(49.55)$ & $25(22.52)$ & $27(24.32)$ & $4(3.60)$ & $8.74 \pm 3.23$ \\
\hline
\end{tabular}

In Table 2, it indicates the effect of patient's element which can affect patient's anxiety status or depression status. In the result, the noteworthy elements contain the average monthly income of the family, pay method, history of smoking, sleep condition, that their research result are statistical significance.

Table 2. Different general data the incidence of preoperative anxiety/depression in patients with thyroid cancer.

\begin{tabular}{|c|c|c|c|c|c|c|}
\hline \multirow{2}{*}{ Project. } & & \multirow{2}{*}{ Total. } & \multicolumn{2}{|c|}{ Anxiety/ Depression [N (\%)] } & \multirow{2}{*}{$\mathrm{X}^{2}$} & \multirow{2}{*}{ P-value. } \\
\hline & & & Yes & No & & \\
\hline \multirow{2}{*}{ Gender. } & Man. & 26 & $15(57.69)$ & $11(42.31)$ & \multirow{2}{*}{0.182} & \multirow{2}{*}{0.669} \\
\hline & Woman. & 85 & $53(62.35)$ & $32(37.65)$ & & \\
\hline \multirow{4}{*}{ Age (year) } & $\leq 35$ & 34 & $23(64.65)$ & $11(32.35)$ & \multirow{4}{*}{5.358} & \multirow{4}{*}{0.147} \\
\hline & $36 \sim 49$ & 48 & $24(50)$ & $24(50)$ & & \\
\hline & $50 \sim 69$ & 27 & $19(70.37)$ & $8(29.63)$ & & \\
\hline & $\geq 70$ & 2 & $2(100)$ & $0(0)$ & & \\
\hline \multirow{2}{*}{ Education } & Junior high school and below & 40 & $17(42.50)$ & $23(57.5)$ & \multirow{2}{*}{9.275} & \multirow{2}{*}{0.002} \\
\hline & High school and above & 71 & $51(71.83)$ & $20(28.17)$ & & \\
\hline \multirow{3}{*}{$\begin{array}{l}\text { The state of the } \\
\text { occupation }\end{array}$} & Working & 73 & $45(61.64)$ & $28(38.36)$ & \multirow{3}{*}{2.929} & \multirow{3}{*}{0.231} \\
\hline & Retired. & 24 & $17(70.83)$ & $7(29.17)$ & & \\
\hline & Unemployed. & 14 & $6(42.86)$ & $8(57.14)$ & & \\
\hline \multirow{4}{*}{$\begin{array}{l}\text { The average monthly } \\
\text { income of the family }\end{array}$} & $<1000$ yuan & 8 & $7(87.50)$ & $1(12.5)$ & \multirow{4}{*}{9.271} & \multirow{4}{*}{0.026} \\
\hline & $1000-3000$ & 65 & $42(64.62)$ & $23(35.38)$ & & \\
\hline & $3001-5000$ & 31 & $18(58.06)$ & $13(41.94)$ & & \\
\hline & $>5000$ yuan. & 7 & $1(14.29)$ & $6(85.71)$ & & \\
\hline \multirow{2}{*}{ Pay Method } & Health care. & 95 & $53(55.79)$ & $42(44.21)$ & \multirow{2}{*}{8.315} & \multirow{2}{*}{0.004} \\
\hline & Self -. & 16 & $15(93.75)$ & $1(6.25)$ & & \\
\hline \multirow{3}{*}{ The state of marriage } & Married. & 81 & $51(62.96)$ & $30(37.04)$ & \multirow{3}{*}{2.061} & \multirow{3}{*}{0.357} \\
\hline & Unmarried/divorced. & 28 & $15(53.57)$ & $13(46.43)$ & & \\
\hline & Widowed. & 2 & $2(100)$ & $0(0)$ & & \\
\hline \multirow{2}{*}{ A history of surgery } & Yes. & 12 & $7(58.33)$ & $5(41.67)$ & \multirow{2}{*}{0.049} & \multirow{2}{*}{0.826} \\
\hline & No. & 99 & $61(61.62)$ & $38(38.38)$ & & \\
\hline \multirow{4}{*}{$\begin{array}{l}\text { Familiarity with } \\
\text { surgery }\end{array}$} & I don't know much about it. & 12 & $8(66.67)$ & $4(33.33)$ & \multirow{4}{*}{2.707} & \multirow{4}{*}{0.439} \\
\hline & General understanding. & 62 & $36(58.06)$ & $26(41.94)$ & & \\
\hline & Familiar with. & 28 & $20(71.43)$ & $8(28.57)$ & & \\
\hline & Very familiar. & 9 & $4(44.44)$ & $5(55.56)$ & & \\
\hline
\end{tabular}




\begin{tabular}{|c|c|c|c|c|c|c|}
\hline \multirow{2}{*}{ Project. } & & \multirow{2}{*}{ Total. } & \multicolumn{2}{|c|}{ Anxiety/ Depression [N (\%)] } & \multirow{2}{*}{$\mathbf{X}^{2}$} & \multirow{2}{*}{ P-value. } \\
\hline & & & Yes & No & & \\
\hline \multirow{2}{*}{ History of smoking } & Yes. & 27 & $12(44.44)$ & $15(55.55)$ & \multirow{2}{*}{4.252} & \multirow{2}{*}{0.039} \\
\hline & No. & 84 & $56(66.67)$ & $28(33.33)$ & & \\
\hline \multirow{2}{*}{ A history of drinking } & Yes. & 18 & $13(72.22)$ & $5(27.78)$ & \multirow{2}{*}{1.088} & \multirow{2}{*}{0.297} \\
\hline & No. & 93 & $55(59.14)$ & $38(40.86)$ & & \\
\hline \multirow{2}{*}{ Sleep conditions } & Good. & 71 & $36(50.70)$ & $35(49.30)$ & \multirow{2}{*}{9.253} & \multirow{2}{*}{0.002} \\
\hline & Poor. & 40 & $32(80)$ & $8(20)$ & & \\
\hline
\end{tabular}

The Table 3 shows logistic regression analysis of anxiety and depression in patients with thyroid cancer before operation. It indicates all data and research results are representative in this study, the samples are enough.

Table 3. Logistic regression analysis of anxiety and depression in patients with thyroid cancer before operation.

\begin{tabular}{|c|c|c|c|c|c|c|}
\hline Projects & B & S. $\mathbf{E}$ & Wald & $\mathbf{P}$ & OR & $95 \% \mathrm{CI}$ \\
\hline Education & 1.018 & 0.518 & 3.859 & 0.049 & 2.767 & $1.002-7.639$ \\
\hline The average monthly income of the family & -2.726 & 1.593 & 2.929 & 0.087 & 0.065 & $0.003-1.486$ \\
\hline Payment is at one's own expense & 2.166 & 1.095 & 3.915 & 0.048 & 8.726 & $1.021-74.598$ \\
\hline no history of smoking & 0.456 & 0.540 & 0.715 & 0.398 & 1.578 & $0.548-4.546$ \\
\hline Poor sleep quality & 1.090 & 0.523 & 4.341 & 0.037 & 2.975 & $1.067-8.295$ \\
\hline
\end{tabular}

\section{Discussion and Conclusion}

Thyroid cancer accounts for about $1 \%$ of all malignant tumors in the whole body. The incidence of thyroid cancer in women is significantly higher than that in men, ranking 8th among common malignant tumors in women and 18th among men [17]. The incidence rate in China is about 7.7 per 100,000 people per year, showing a younger trend. In addition, some patients had lymph node metastasis or distant metastasis at the time of diagnosis, and surgical treatment is mainly used in clinical practice at present [18]. In prognosis of thyroid carcinoma, if adenocarcinoma has a good prognosis, postoperative complications such as hoarseness, dyspnea, and thyroid crisis may also occur, because the dense distribution of blood vessels and nerves around the thyroid gland [19]. In the preoperative, Anxiety and depression are common psychological reactions, mainly manifested as excessive worry about surgery and illness. Mild symptoms are accelerated heartbeat, restlessness, frequent urination, nausea, dizziness, loss of appetite, insomnia. Severe cases may have adverse effects on postoperative recovery [5].

Based on the above results, the important factors of anxiety and depression include Education level in high school or above, payment at their own expense and poor sleep quality in patients with thyroid cancer before surgery. Additionally, anxiety and depression have higher incidence rate in patients with high education level than in patients with low education level. Because highly educated people tend to know various information about the disease, have high expectations for the disease and worry about the effect of surgery. Self-financed patients worry that treatment will burden them and their families so much that they become more anxious and depressed. Sleep quality is related to mental health, patients with poor sleep quality have more negative emotions. So medical staff should not only pay attention to the anxiety and depression of patients with thyroid cancer before surgery, but also provide timely and necessary psychological counseling and intervention for special groups, including high school education group, own expense group and poor sleep quality group. In similar, Fugazzola's report indicates that thyroid carcinoma patients are affected easily by sleep quality and education level of patient. But his patients are not affected by payment methods, the reason may is that they have different Medical benefits from government so that their patients did not need to suffer more anxiety and depression from patient's financial situation [7].

\section{References}

[1] Siegel RL, Miller KD, Jemal A. Cancer Statistics, 2017. CA Cancer J Clin. 2017; 67: 7.

[2] Li M, Dal L, Maso K, Vaccarella S. Global trends in thyroid cancer incidence and the impact of overdiagnosis, Lancet Diabetes Endocrinol. 2020; 8: 468-470.

[3] Gianola D, Schon CC. Cross-validation without doing cross-validation in genome-enabled prediction. 2016; 6 (10): 3107.

[4] Handkiewicz-Junak D, Czarniecka A, Jarzab B. Molecular prognostic markers in papillary and follicular thyroid cancer: current status and future directions, Mol. Cell. Endocrinol. 2016; 322 (1): 8-28.

[5] Cabanillas E, McFadden DG, Durante C. Thyroid cancer, Lancet. 2016; 388 (10061): 2783-2795.

[6] Nguyen DT, Lee EJ, Huang MG, Park YI, Khullar A, Plodkowski RA. Diagnosis and treatment of patients with thyroid cancer. Am. Health Drug Benefits. 2015; 8 (1): 30-40.

[7] Fugazzola I, Elisei R, Fuhrer D, Jarzab B, Leboulleux S, Newbold K, Smit J. 2019 European thyroid association guidelines for the treatment and follow-up of advanced radioiodine-refractory thyroid Cancer. European Thyroid Journal. 2019; 8 (5): 227-245. 
[8] Kaltschmidt C, Banz-Jansen C, Benhidjeb T, Beshay M, Förster C, Greiner J, Hamelmann E, Jorch N, Mertzlufft F, Pfitzenmaier J, Simon M, SchulteAm Esch J, Vordemvenne T, Wähnert D, Weissinger F, Wilkens L, Kaltschmidt B. A role for NF- $\mathrm{kB}$ in organ specific cancer and cancer stem cells. Cancers (Basel). 2019; 11 (5): 655.

[9] Vaccarella S, Dal Maso L, Laversanne M, Bray F, Plummer M, Franceschi S. Theimpact of diagnostic changes on the rise in thyroid cancer incidence: apopulation-based study in selected high-resource countries. Thyroid. 2015; 25: 1127-1136.

[10] Haugen BR, Alexander EK, Bible KC, et al. 2015 American Thyroid Associationmanagement guidelines for adult patients with thyroid nodules and differentiatedthyroid cancer: The American Thyroid Association Guidelines Task Force on Thyroid Nodules and Differentiated Thyroid Cancer. Thyroid. 2016; 26: 1-133.

[11] Chen W, Sun K, Zheng R, et al. Cancer incidence and mortality in China, 2014. Chin J Cancer Res. 2018; 30: 1-12.

[12] Davies L, Morris LG, Haymart M, et al. American Association of Clinical Endocrinologists and American College of Endocrinology disease state clinical review: the increasing incidence of thyroid cancer. Endocr Pract. 2015; 21: 686-696.

[13] Shi LY, Liu J, Yu LJ, et al. Clinic-pathologic features and prognostic analysis of thyroid cancer in the older adult: a SEER based study. J Cancer. 2018; 9: 2744-2750.

[14] White D, Leach C, Sims R, Atkinson M, Cottrell D. Validation of the Hospital Anxiety and Depression Scale for use with adolescents. Br J Psychiatry 1999; 175: 452-454.

[15] El-Rufaie O, Absood G. Validity study of the Hospital Anxiety and Depression Scale among a group of Saudi patients. Br J Psychiatry 1987; 151: 687-688.

[16] Fahad SL, Aymen ME, Saadia I, Adeel AK, Unaib R. Psychometric properties of the Urdu version of the Hospital Anxiety and Depression Scale (HADS) among pregnant women in Abbottabad, Pakistan. General Psychiatry. 2020; 33 (5).

[17] Wang M, Chen B, Ru C, Cong L. CircRNA circ-ITCH suppresses papillary thyroid cancer progression through miR-22-3p/CBL/ $\beta$-catenin pathway, Biochem. Biophys. Res. Commun. 2018; 504: 283-288.

[18] Wu C, Liu J, Liu S, et al. Assessment of the health risks and odor concentration of volatile compounds from a municipal solid waste landfill in China. Chemosphere. 2018; 202: 1-8.

[19] Antognelli C, Moretti S, Frosini R, Puxeddu E, Sidoni A, Talesa VN. Methylglyoxal acts as a tumor-promoting factor in anaplastic thyroid cancer. Cells. 2019; 8 (6): 547. 